\title{
Neurobehavioral perspectives on the distinction between fear and anxiety
}

\author{
Jennifer N. Perusini ${ }^{1,2}$ and Michael S. Fanselow ${ }^{3,4}$ \\ ${ }^{1}$ Department of Psychiatry, Columbia University, New York, New York 10032, USA; ${ }^{2}$ Division of Integrative Neuroscience, New York \\ State Psychiatric Institute (NYSPI)/Research Foundation for Mental Hygiene, Inc. (RFMH), New York, New York 10032, USA; \\ ${ }^{3}$ Department of Psychology, ${ }^{4}$ Department of Psychiatry and Biobehavioral Sciences, University of California at Los Angeles, \\ Los Angeles, California 90095, USA
}

\begin{abstract}
In this review, we discuss the usefulness of the distinction between fear and anxiety. The clinical use of the labels is ambiguous, often defining one in terms of the other. We first consider what a useful, objective, and scientifically valid definition would entail and then evaluate several fear/anxiety distinctions that have been made in the neurobiological literature. A strong distinction should specify the difference in conditions that lead to fear versus anxiety. Additionally, fear and anxiety should generate distinct sets of behaviors. Ideally, the two states should be supported by distinguishable neuroanatomical circuits. Such a conceptualization would be consistent with the National Institute of Mental Health's Research Domain Criteria (RDoc). The majority of neurobiological approaches to the fear versus anxiety distinction fail to differentiate the two states in terms of behavior, often using the exact same behavioral measures as indicators. Of the two that do, only Predatory Imminence Theory provides a distinction both in terms of cause and effect. Indeed, that approach provides a ready distinction of anxiety, fear, and panic in terms of both antecedent conditions and response selection rules. Additionally, it appeals to distinct neural circuits to generate these modes of action.
\end{abstract}

Clear definitional distinctions between fear and anxiety have been elusive. There is also ambiguity in relating clinical classifications to preclinical laboratory models. The intention of this review is to describe and evaluate several neurobehavioral approaches to the distinction between fear and anxiety. A clear, research-based definition of fear and anxiety should help clarify the natural function of these brain states and point to how their dysfunction manifests as particular anxiety disorders. This relationship is becoming increasingly important with the National Institute of Mental Health's adoption of Research Domain Criteria (RDoc), which specifically attempts to link preclinical research with clinical phenomenology. The purpose of the RDoc systems is to "...to translate rapid progress in basic neurobiological and behavioral research to an improved integrative understanding of psychopathology and the development of new and/or optimally matched treatments for mental disorders" (National Institute of Mental Health 2013).

To accomplish this goal, we will first consider the characteristics of a good definitional distinction between fear and anxiety. Then, after briefly reviewing the circuitry responsible for fear and anxiety, we will evaluate several neurobehavioral models with respect to those characteristics. Parsing the strengths and weaknesses of these models as well as analyzing the mechanisms and circuitry that underlie fear learning may point toward a better understanding of the fear/anxiety distinction. It should also help forge a clearer relationship between these models and specific anxiety disorders. We also clarify the relationship of the RDoc criteria to these animal models.

\section{Distinguishing fear and anxiety: metatheoretical considerations}

Fear and anxiety are theoretical constructs and such constructs are of value only if they explain and predict behavior (Bolles 1975).

\section{Corresponding author: fanselow@psych.ucla.edu}

Article is online at http://www.learnmem.org/cgi/doi/10.1101//m.039180.115.
The most valuable theoretical constructs are intervening variables that serve to mediate between cause and effect. Therefore, it is important to consider what is required of such constructs at a formal theoretical level (Bolles 1975). First, if fear and anxiety are different, then they should have different antecedent conditions; they should be caused by different precipitating events. Second, fear or anxiety activation should have different consequences; they should manifest as different behaviors. If these two conditions are met, then fear and anxiety would both be valuable and not redundant constructs. If they cannot be met, there is little value in having two separate constructs. We will use these criteria in our evaluation of preclinical animal models that attempt to differentiate fear and anxiety.

While a distinction between fear and anxiety is made in both clinical and preclinical literature, there are no uniform or consistent definitions of these terms that elevate these constructions beyond subjective status. That is, there are no clear distinctions of the differential causes of fear versus anxiety, nor are there clear differences in the responses they are said to generate. For example, one popular distinction is that while fear occurs in response to a specific object, anxiety does not have a specific eliciting stimulus. Simple or specific phobia is by definition a response to a specific stimulus and therefore fear, rather than anxiety, would seem to be the relevant term. In the Diagnostic and Statistical Manual of Mental Disorders (DSM)'s description of anxiety disorders, a place where one might go for clarification, the descriptions are unclear, inconsistent, and often define one in terms of the other. So, according to the DSM, "specific phobia is marked as persistent fear of clearly discernible, circumscribed objects or situations. Exposure to the phobic stimulus invariably provokes an immediate anxiety response"

(C) 2015 Perusini and Fanselow This article is distributed exclusively by Cold Spring Harbor Laboratory Press for the first 12 months after the full-issue publication date (see http://learnmem.cshlp.org/site/misc/terms.xhtml). After 12 months, it is available under a Creative Commons License (AttributionNonCommercial 4.0 International), as described at http://creativecommons. org/licenses/by-nc/4.0/. 
(American Psychiatric Association 2013). Thus, this definition states that anxiety occurs in response to a specific stimulus thereby undermining a commonly used distinction.

Throughout the DSM, there is little clarity as to what clinical conditions are accompanied by fear versus anxiety. Thus, "social anxiety disorder is a marked, or intense, fear or anxiety of social situations" and specific phobia is a "marked fear or anxiety about a specific object or situation." Therefore, the remainder of this article will examine concepts arising from neurobiological studies and consider what traction they can apply to separating fear and anxiety. In order to do so, we must first consider the neural circuitry most closely linked to fear and anxiety.

\section{Neural circuitry}

Neurobehavioral studies have identified components of a core circuit that is thought to produce and regulate both fear and anxiety. Pavlovian fear conditioning has been the principle tool in unraveling this circuitry. During fear conditioning, an aversive unconditional stimulus (US), such as a footshock, becomes associated with an initially nonfearful stimulus such as a tone or the context (chamber) in which training takes place. As a result, the previously nonfearful stimulus now becomes a conditional stimulus (CS) that provokes a number of quantifiable responses, including freezing, potentiation of startle, analgesia, and hypertension, in the absence of the US. These responses to fear are the species-specific defense reactions that evolved to protect us from threats (Bolles 1970; Bolles and Fanselow 1980; Fanselow 1984). Thus, the circuitry that underlies fear is this defensive behavioral circuitry (Fanselow 1994).

This description of Pavlovian fear conditioning helps provide an objective, cause-and-effect definition of fear. Fear is caused by stimuli that predict danger (i.e., a CS or an innate danger stimulus; Fanselow and Sigmundi, 1986) and the effect of fear is to produce defensive behavior mediated by activation of the appropriate circuits serving these behaviors. For us, there is a one-to-one mapping between fear and what happens in a fear-conditioning experiment. This definitional scheme differs from that of LeDoux (2014) who argues that the term "fear" should be reserved for the subjective conscious state that the layman labels as fear. This subjective experience may be in part caused by activation of defensive circuits and in part by other aspects of conscious experience quite separate from the arousal of defensive circuitry. Also, in LeDoux's view, there may be aspects of activation of defensive circuits that are not available to conscious experience and therefore are not part of the fear experience. As an alternative label, LeDoux suggests that we refer to the actions generated by activation of defensive circuits (e.g., via fear conditioning) by threat behavior. Thus, LeDoux abandons the one-to-one mapping of fear and the activation of the defensive behavior system and embraces a more experiential and subjective definition of fear. We disagree and instead argue that one goal of science is to replace inaccurate subjective explanations of our feelings and actions with more precise and scientifically grounded explanations of these phenomena. We believe that our approach provides key insights into the biological functions of fear and anxiety that will help the layperson understand his/her experience and push toward a more complete understanding of the neurobiology of defensive behavior. We share LeDoux's view that fear conditioning (threat conditioning) results in the activation of innate defensive behavior circuits and that the science of fear requires complete and clear definitions of its terminology. In this review, that is what we hope to do for both fear and anxiety.

Figure 1 presents a general model of the neural circuitry of fear and anxiety. The basolateral amygdala (BLA), which consists

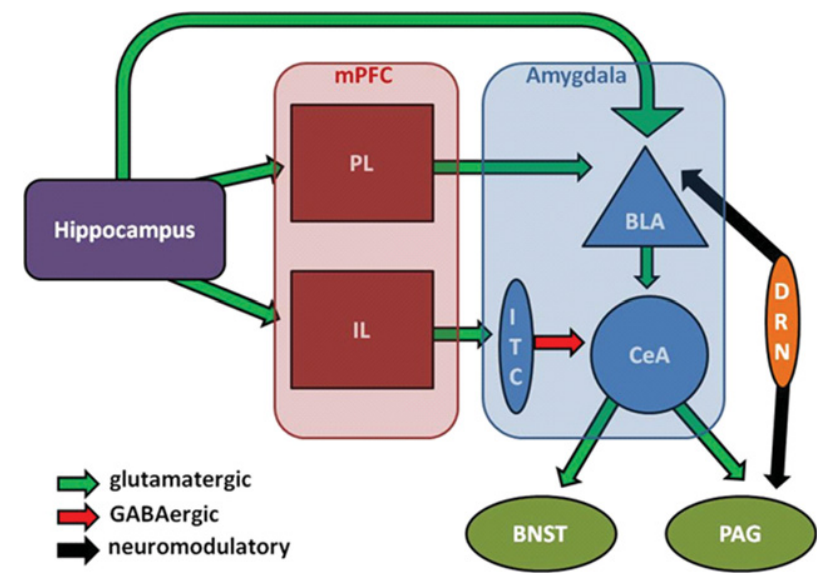

Figure 1. Circuit diagram depicting a general model of neural circuitry of fear and anxiety. The basolateral amygdala (BLA) gathers sensory information from both thalamic and auditory cortical regions, both involved in relaying CS (e.g., tone) information, as well as from the hippocampus for contextual information. The BLA projects to the central nucleus (CeA) both directly and indirectly, via the GABAergic intercalated cell (ITC) masses that lie between these two regions. The CeA output to the periaqueductal gray (PAG) and bed nuclei of the stria terminalis (BNST) drive fear responding. Ascending projections from the brainstem and midbrain to the amygdala, such as from the dorsal raphe nucleus (DRN) projects to the dorsal PAG and to the amygdala in a manner that modulates defensive behaviors. Descending projections from the medial prefrontal cortex also differentially modulate the behavioral outputs of this circuit-the prelimbic $(\mathrm{PL})$ cortex projects to the BLA possibly to enhance fear responding while the infralimbic cortex (IL) indirectly projects to the CeM via ITC to mediate extinction. Green arrows represent glutamatergic projections, red arrows represent GABAergic projections, and black arrows represent neuromodulatory projections (e.g., DRN to BLA is serotonergic).

of the lateral and basal nuclei, acts as a hub for fear learning, gathering sensory information and instigating behavioral output. It receives inputs from both thalamic and auditory cortical regions, both involved in relaying CS (e.g., tone) information. For context conditioning, the BLA receives inputs from the hippocampus (Maren and Fanselow 1995). Contextual/tone information and US information converge onto single cells in the BLA (Romanski et al. 1993; Barot et al. 2009; Chung et al. 2011). N-Methyl-Daspartate receptor (NMDAR)-dependent synaptic plasticity in the BLA is critical for fear learning, and coincident detection of CS and US information must occur. For instance, APV, an NMDAR antagonist, delivered into the BLA prevents acquisition of fear (Miserendino et al. 1990; Fanselow and Kim 1994).

The BLA projects to the central amygdala (CeA) both directly and indirectly, via the intercalated cell (ITC) masses that lie between these two regions (Pitkanen et al. 1997; Paré et al. 2004). Specifically, lateral nucleus neurons project to the lateral subdivision of central nucleus (CeL), which sends GABAergic projections to the medial subdivision of the central nucleus (CeM) (Haubensak et al. 2010). The basal nuclei project both directly to the medial subdivision of the central nucleus (CeM) and indirectly via ITC neurons. Thus, the ITC, which are GABAergic cell clusters lying in the fiber tract separating BLA and CeA, provide an effective relay between the BLA and CeA. Fear responses are controlled by descending projections from CeM, which targets structures such as the periaqueductal gray (PAG) to drive freezing and several other defensive behaviors (Fanselow 1991). Besides the CeA, the BLA project to the bed nuclei of the stria terminalis (BNST), which in turn projects to the PAG to drive fear responding (Walker et al. 2003; Waddell et al. 2006; Poulos et al. 2010). Moreover, there are also ascending projections from the brainstem and midbrain to 
the amygdala (Li et al. 1990). The dorsal raphe nucleus (DRN) projects to the dorsal PAG and to the amygdala. Prior exposure to inescapable shock alters subsequent fear conditioning at least in part mediated by ascending projections from the DRN to amygdala (Maier et al. 1993). The PAG also contains topographically organized reciprocal connections with the amygdala in order to integrate the cognitive and autonomic components of emotional behavior (Rizvi et al. 1991). These ascending projections contribute to the "teaching signal" that drives fear learning (Johansen et al. 2010).

Descending projections from the medial prefrontal cortex (mPFC) also modulate the behavioral outputs of this circuitthe prelimbic (PL) cortex projects to the BLA possibly to enhance fear responding. The infralimbic cortex (IL) indirectly projects to the CeM via intercalated cells in rats but not in mice (Pinto and Sesack 2000, 2008; Strobel et al. 2015). It is thought that the ITC cells mediate extinction (Quirk et al. 2003; Likhtik et al. 2008) but may play a more general role in gating fear behavior, as they also receive direct sensory inputs (Asede et al. 2015; Strobel et al. 2015). Moreover, PL and IL receive amygdala projections originating mainly from the basal amygdala. IL and PL have opposing roles in expression of fear following extinction learning (Senn et al. 2014), which suggests that these reciprocal connections influence the outcome of fear and extinction learning. Inputs from the ventral hippocampus onto the basal amygdala mediate contextual fear (Maren and Fanselow 1995; Hübner et al. 2014). Additionally, the ventral hippocampus, either directly or indirectly through PL, mediates contextual control of fear renewal after extinction (Orsini et al. 2011). Figure 1 provides a simple outline for the neural circuitry discussed in this section and throughout the review.

\section{Neurobehavioral models of fear and anxiety}

\section{Pavlovian fear conditioning}

In the previous section, we described how associative fear conditioning was used as a tool to develop a circuit-level understanding of aversively motivated behavior. Fear conditioning was also the first laboratory model of fear and anxiety. The first fear conditioning experiment was the infamous Little Albert study by Watson and Rayner (1920), which described Albert's laboratory-induced fear of a rat as a "conditioned emotional response" and suggested that this was the way in which phobias were generated. Watson used the term fear, but not anxiety, in his description of the Little Albert study. In contrast, when Estes and Skinner (1941) developed conditioned suppression of food-reinforced lever pressing as a measure of fear conditioning, they called it a quantitative measure of anxiety. The ambiguity of the terms fear and anxiety was present even in two of the most extreme behaviorists and earliest practitioners of fear conditioning (i.e., Skinner and Watson). Thus, historically, fear conditioning has not differentiated between these terms.

One potential distinction between fear and anxiety made within the fear-conditioning literature is that responding to an explicit cue paired with shock (e.g., a brief tone) models fear, while responding to contextual cues paired with shock models anxiety. The logic is that contextual cues are more vague and prolonged and are therefore more akin to anxiety than fear. Furthermore, it was believed that the circuitry underlying contextual fear is somewhat different than for cued fear, as contextual, but not cued, fear depends on the dorsal hippocampus and BNST (Kim and Fanselow 1992).

There are several problems in considering the differences between cued and contextual fear as analogous to the fear and anxiety distinction. First, the idea that contextual fear is caused by a vague stimulus ignores the fact that context fear is very dependent on recognition of the specific features of the context and their configuration (Fanselow 1981; Rudy and O'Reilly 1999). The idea that contextual stimuli are more prolonged than explicit cues also has no merit. One-trial contextual conditioning has been demonstrated with a contextual presentation as short as 17 sec (Landeira-Fernandez et al. 2006). On the other hand, many of the classic cued conditioning phenomena used tone CSs 3 min in duration, and fear conditioning with long-duration cues depends on the BNST (Kamin 1969; Waddell et al. 2006). Thus, in terms of the defining antecedent conditions, the distinction between contextual and cued conditioning bears little relation to the fear and anxiety distinction. Problems arise on the consequent end as well as cued and contextual fear produce the same suite of responses. Thus, contextual versus cued conditioning fails all of our criteria for a fear/anxiety differentiation.

What then does fear-conditioning model? The analogy of fear conditioning to phobia is quite clear; there is a fear of something that is not normally feared. If someone is afraid of dogs because he/she was attacked by a dog in the past, it is easy to see this as a phobia caused by fear conditioning. The dictionary definition of a phobia is an "irrational fear of a specific object, activity, or situation" (American Psychiatric Association 2013). The inclusion of object and situation includes both cued and contextual conditioning. The problem comes from the definition of irrational. The dog phobic was attacked by a dog, so dogs are truly dangerous. Nothing is "irrational" about such a fear. Generally, fear conditioning produces a fear that grades well with respect to the degree of threat. Fear conditioning increases as both shock intensity (current) and frequency (trials) increases (Annau and Kamin 1961; Fanselow and Bolles 1979a; Young and Fanselow 1992). Thus, in this sense fear conditioning produces rational behavior. A clinical diagnosis is more forthcoming if the fear interferes with normal functioning; which may or may not be the case with our aforementioned dog phobic. Thus, phobias may be best thought of as a fear of a specific stimulus that when severe enough to impinge on everyday function requires clinical treatment (see "Inhibiting Fear" below). In this case, fear conditioning provides a good model of the etiology and treatment of phobias. Indeed, in this case, "model" really means replica; the rat in Estes and Skinner's (1941) experiment had a phobia of a tone severe enough to stop it from eating when hungry. Indeed, the tone caused more suppression than the shock itself. Thus, fear conditioning relates best to the state that accompanies phobia. We will call that state fear, but will have more to say about why we chose this term when we describe Predatory Imminence Theory.

\section{Acute versus sustained threat}

Davis and colleagues have made a distinction between sustained and acute threat and proposed that it relates to the differences between fear and anxiety. According to their model, when an acute threat is present, the BLA-CeA-brainstem circuit is activated and fear responding ensues. However, besides the CeA, the BLA projects to the BNST for sustained fear responding and fear conditioning with a longer-duration CS (Fig. 1; Walker et al. 2003; Waddell et al. 2006). Responses elicited by both a long duration bright light $\mathrm{CS}$ and corticotropin releasing hormone (CRH) administration, while still BLA-dependent, do not depend on the CeA but instead the BNST (Lee and Davis 1997; Walker and Davis 1997). Also, BNST lesions reduce fear conditioning when long, but not short, CSs are used and this occurs with both auditory and contextual CSs (Waddell et al. 2006).

The perspective from the Davis laboratory is that the BNST play a complimentary role to the CeA, both are viewed as response-driving descending output structures that are engaged 
by the BLA. However, the studies from Bouton's laboratory suggest that the BNST are critical to the acquisition of fear to long duration CSs rather than the expression of fear (Waddell et al. 2006). Therefore, the Bouton experiments cast the BNST in a new light, that they are significant contributors to some aspect of cognitive processing when long-duration fear cues are used.

The BNST are abundant in CRH receptors, and intra-BNST infusions of $\mathrm{CRH}$ in rats enhance startle. The CRH system and the BNST are also critical for reinstating fear, which will be discussed in the "Inhibiting Fear" section (Waddell et al. 2006). This distinction between CeA mediated acute fear and BNST-mediated sustained fear underlies the RDoc's distinction between responses to acute threat and sustained threat.

The sustained/acute model clearly specifies independent sets of stimuli that activate the sustained versus acute response, thus meeting the antecedent requirements for a useful distinction between fear and anxiety. However, the model does not do well in terms of differentiating the responses that result from fear versus anxiety. The BNST project to the same targets as the CeA, including the PAG, so the behavioral responses elicited by a sustained threat may be indistinguishable from responses elicited by an acute threat. Indeed, Davis et al. (1997) initially looked to the BNST because of its similarity of projections to the CeA. Consistent with this, Davis (potentiated startle) and Bouton (conditioned suppression) used the same response endpoints to measure acute versus sustained responding. It should be noted that Waddell et al. (2006) reported that BNST lesions increased time in the open quadrant of a circular maze. However, they did not show that these responses did not accompany fear conditioning with the brief CS or that these responses were not affected by CeA lesions, both of which are necessary if one is to uniquely link this alteration in exploration to the sustained condition. However, like BNST lesions, CeA lesions increase time in the open arm of an elevated plus maze in stressed animals (VenturaSilva et al. 2013), suggesting that there is little to differentiate sustained versus acute threat in terms of response generation.

While the sustained versus acute threat does not fulfill the requirements for a viable fear anxiety/distinction it does show an important aspect of defensive behavior circuitry. It is quite possible that the BLA uses two parallel pathways to support defensive behavior: a quick rapid but short-lived CeA-mediated output and a more slowly recruited BNST output capable of maintaining similar defensive responses over a longer period. However, additional research is required to isolate how the BNST contribute to both the acquisition and expression of learned fear.

\section{Sensitization of fear circuitry by acute stress}

Stress-enhanced fear learning (SEFL), a rodent model of posttraumatic stress disorder (PTSD), uses both nonassociative and associative fear learning to attempt to elucidate fear versus anxiety. Rats exhibiting SEFL also show an anxiety profile on the elevated plus maze, a long-lasting dysregulation of the diurnal cycle for corticosterone (CORT), and an increase of glucocorticoid receptors (GR) in the BLA (Poulos et al. 2014). Moreover, SEFL-rats acquire increased consumption of alcohol (Meyer et al. 2013). In other words, SEFL behavior reflects several of the symptoms and comorbidities of PTSD.

Rats that receive only a single footshock during conditioning will show modest levels of freezing ( $\sim 25 \%$; e.g., Fanselow and Bolles 1979a). However, if rats received 15 shocks in a different environment prior to conditioning (Context A), the single shock results in much higher levels of freezing ( $>80 \%$-Fanselow and Bolles 1979b). This effect was partially reduced if the 15 shocks were made predictable by preceding them with a 30 -sec signal (Fanselow and Bolles 1979b). One simple explanation of such an effect is that the initial 15-shock experience conditioned fear to the stress environment and that fear generalized to the one-shock context (Context B). However, several findings rule out this interpretation. First, is that the two contexts were sufficiently differentiated so that there is little generalization between environments. Additionally, 15 unsignaled shocks in one context also dramatically increases conditioning to a tone that was paired with one shock in a different environment (Fig. 2; Rau et al. 2005). It is difficult to see what aspect of the 15 unsignaled shocks could have generalized to the tone. In addition, one can eliminate fear of the 15 -shock context but fear conditioning to the single shock is still enhanced. This elimination of fear to the 15 -shock context was done in three different ways. First, completely extinguishing fear of the 15-shock context had no effect on the enhanced conditioning to the single shock (Rau et al. 2005; Long and Fanselow 2012). Poulos et al. (2014) approached the issue developmentally; they applied the 15 shocks at an age in which contextual fear conditioning does not develop (19 d old) and gave the single shock to the rat when it was an adult. A similar dissociation was reported by Quinn et al. (2014). Despite showing no memory of the 15-shock session, conditioning to the single-shock context was still enhanced. Perhaps most dramatically, Rau et al. (2005) gave an intracerebral infusion of the NMDAR antagonist, DL2-amino-nvaleric acid, prior to the stress session. While this manipulation completely blocked contextual fear conditioning to the stress shock context, conditioning to the single shock was still dramatically enhanced. Moreover, exposure to the 15 shocks can convert a weak footshock that normally does not support measurable levels of fear conditioning into one that causes substantial learned fear, and the capacity of the 15 shocks to induce fear sensitization increases as the intensity of the single footshock increases (Poulos et al. 2014).

The experiments described above used a very similar footshock US during the stages of stress and conditioning. However, the effect is not dependent on having a similar stimulus in both the stress and conditioning phases. Maier (1990) reported similar effects when the stress was a tailshock and the US for conditioning was a footshock. Poulos et al. (2014) showed that when the stressor was given to juvenile rats, as adults they displayed

A
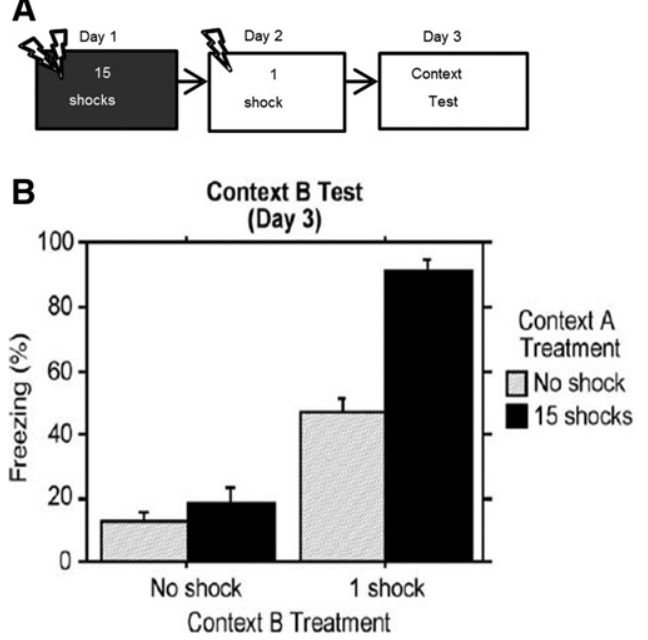

Figure 2. Mean ( \pm SEM) percentage of freezing during the Context $B$ test on day 3. Animals not shocked in Context $B$ showed minimal levels of freezing in Context B. Animals not shocked in Context $A$ and given one shock in Context B showed moderate levels of freezing while animals shocked in both contexts showed a reliably higher percentage of freezing compared to the other groups. (Adapted from Rau et al. 2005.) 
reduced entries in the open arm of an elevated plus maze, which is obviously a situation with no shock at all. Additionally, restraint stress can also enhance acquisition of fear conditioning, so the stressor need not be shock to enhance later conditioning with a shock US (Hoffman et al. 2014). Given that the effect does not depend on associative factors, it appears to be a nonassociative sensitization of fear learning. This sensitization is extremely persistent; it is not diminished even when $90 \mathrm{~d}$ intervenes between stress and conditioning (Rau and Fanselow 2009; Poulos et al. 2014; Quinn et al. 2014). Maier and Watkins (1998) have suggested that this sensitized state corresponds to anxiety. According to such a view, anxiety is a positive modulation of normal fear responding. However, SEFL fails to behaviorally differentiate fear and anxiety-that is, in this model, the consequence of anxiety is to increase fear behaviors (e.g., freezing).

\section{Controllability changes fear and anxiety phenotypes}

In situations where animals receive substantial exposure to uncontrollable and unpredictable stress, in addition to SEFL, they exhibit an inability to perform escape responses (Maier 1984). Inescapable tail shock differentially activates serotonergic cells in the caudal DRN (Grahn et al. 1999) and leads to increases in extracellular serotonin within the DRN (Amat et al. 1998; Maswood et al. 1998), which are important for the production of these anxiety-like behaviors (Maier et al. 1993). CRH has also been shown to enhance DRN serotonergic activity that increases with the inescapable shock procedure (Hammack et al. 2002). These mechanisms may also underlie SEFL. The subsequent interference with escape behavior and the nonassociative increase in fear conditioning produced by inescapable shock are attenuated with intra-DRN administration of CRH receptor antagonists. This approach to the fear/anxiety distinction shares a problem with several of the other models we considered; the behavioral endpoints of fear and anxiety are the same.

The inescapable tailshock procedure described above uses the element of controllability in order to explain how an acute threat may recruit another structure, the DRN, in order to modulate the amygdala and PAG to increase and change fear responding. While this model describes the proper antecedent conditions for an uncontrollable threat and the circuitry it recruits, again, the behavioral phenotype for this anxiety-like condition is not distinguishable from fear behavior. However, this model does suggest that control may mitigate the stress-induced phenotype and implicates a region that may be a potential treatment target, especially for the behavioral consequences of uncontrollable stressors.

\section{Innate anxiety measures}

A number of tasks have been proposed as measures of anxiety (Bailey and Crawley 2009). Several of these examine patterns of exploratory behavior where "anxious" rodents restrict their activity in various ways (e.g., elevated plus maze, open field, light-dark box, and thigmotaxis). Others look at suppression of behavior rodents typically engage in (eating palatable foods in novel environments; investigation of novel conspecifics). These tasks share two commonalities: first, the behaviors require no specific training and second they are assessed in relatively novel environments. The validation of these tests is largely based on the ability for classic anxiolytic compounds (e.g., benzodiazepines) to reduce the target behaviors. These tests emphasize the nonassociative, unlearned component of anxiety. However, the selection of these behaviors is largely based on intuition rather than any rigorous theoretical framework. In particular, they in no way say what the antecedent causes of anxiety are. This creates a great risk of circularity. A drug is considered anxiolytic because it increases entry into the open arm and open arm entries indicate a lack of anxiety because they are increased by the putatively anxiolytic drug. It could be said that since these tasks are typically given in a novel environment, novelty is the antecedent cause of anxiety. However, it is unlikely that novelty is the only cause of anxiety. Furthermore, one could just as easily say that novelty produces fear and these tests reflect fear. That is rodents are afraid of heights (elevated plus maze), open spaces (open field) or the light (lightdark box). Finally, even the relationship to novelty is tenuous because experience with the elevated plus maze will tend to decrease open arm entries on a subsequent test, suggesting that familiarity causes increased anxiety (Rodgers and Shepherd 1993). Thus, while these tasks are useful in helping to develop a full categorization of behavior, they offer little insight into the distinction between fear and anxiety. What is needed is to integrate these behaviors into a more comprehensive and rigorous model of defensive behavior. We consider such a model next.

\section{Predatory imminence theory}

Over the course of evolution, all living organisms developed a repertoire of adaptive responses to evade a range of threats (Bolles 1970). Under conditions of threat an animal's behavioral repertoire becomes limited to these species specific defense reactions. Since each species has several defensive responses available a critical question is how an animal matches a particular threat with the most appropriate defensive behavior. Fanselow and Lester (1988) proposed a response-selection rule based on a series of fear conditioning experiments, where it is the prey's perception of the likelihood of being consumed by a predator that determines the defensive behavioral topography. They suggested that defensive behaviors fall along a predatory imminence continuum (Fanselow and Lester 1988). Imminence is influenced by spatial and temporal distance of the predator. The dimension is one of psychological distance from the predator that is determined by physical, temporal, and probabilistic closeness to contact with the threat. Characteristics of threat also determine imminence; so, for example, a gazelle flees from a lion before it flees from a hyena (Walther 1969). Defensive behaviors are divided into three stages or modes (Timberlake and Lucas 1989)—pre-encounter, post-encounter, and circa-strike (see Fig. 3). Pre-encounter-defensive behaviors include meal reorganization and cautiousness in leaving the nesting area. Post-encounter defense is mostly characterized by freezing in rats to decrease detection and attack, but will be abandoned once the predator makes or is about to make contact. At that point, circa-strike defensive behavior ensues, which includes biting, jumping, and vocalizations. While the continuum of defensive behaviors are most easily described in terms of physical distance between predator and prey (Fanselow and Lester 1988; Blanchard et al. 1989), behaviors within each mode increase as shock density increases, up to a point at which the mode of defense changes and the next set of behaviors emerges (Fanselow 1989; Helmstetter and Fanselow 1993). Therefore, responses may actually be controlled by different levels of a single construct (i.e., different levels of imminence), where intensity is read out as different behaviors (Kunwar et al. 2015). It should be noted that Predatory Imminence Theory is an example of a more general approach called functional behavior systems, that has been successfully applied to the motivation for food and sex (Domjan 1994; Fanselow 1994; Timberlake 1994; Timberlake and Fanselow 1994).

\section{Three modes of defense}

"Pre-encounter reactions," in which harm may potentially occur but is distant or low in probability, are characterized by a pattern of responses such as enhanced vigilance and risk assessment. 


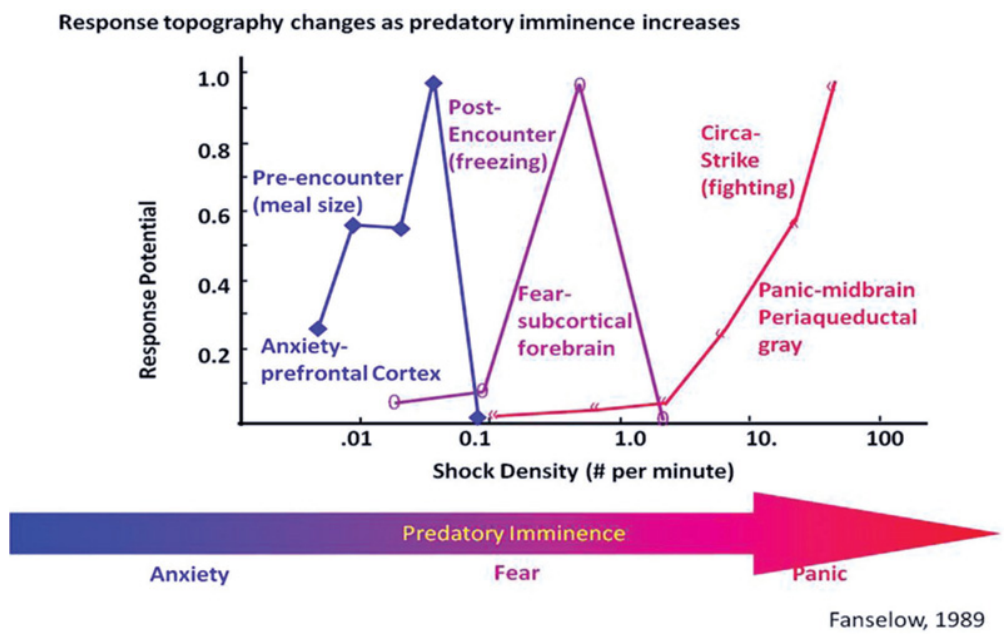

Figure 3. Defensive behaviors fall along a predatory imminence continuum. Imminence is influenced by spatial and temporal distance of the predator. Defensive behaviors are divided into three stages, or modes-pre-encounter, post-encounter, and circa-strike. Pre-encounter defensive behaviors rely on the prefrontal cortex and include meal reorganization and cautiousness in leaving the nesting area. Post-encounter defense is characterized by freezing in rats to decrease detection and attack, driven by the medial prefrontal cortical (mPFC) to amygdala to PAG network; however, these behaviors will be abandoned once the predator makes or is about to make contact. At that point, circa-strike defensive behavior ensues, mediated by regions such as the dorsolateral PAG, which includes biting, jumping, and vocalizations. This continuum of defensive behaviors can also be applied to shock behaviors; as shock density increases, the mode of defense changes and the next set of behaviors emerges (Fanselow 1989; Helmstetter and Fanselow 1993). From this perspective, anxiety disorders are a distortion of predatory imminence, such that defensive behaviors intrude into normal daily range of activities. (Adapted from Fanselow 1989.)

These responses to low imminence threats are qualitatively different than the high imminence threat behaviors that characterize fear, and may better characterize anxiety. They have also been shown to be related to activation of the BNST (Walker et al. 2003) and possibly PFC (Mobbs et al. 2009). One example of pre-encounter defense is when a safe nesting area is left to forage in a potentially dangerous environment. In such a situation, rats reorganize their meals patterns to minimize their risk (Fanselow and Lester 1988; Fanselow et al. 1988). In these situations, rats will leave the nesting area using a stretched approach behavior. It has been speculated that the stretch approach posture may provide an opportunity for information gathering and risk assessment (Pinel et al. 1994). The innate tests of anxiety described above (light-dark box, open field, elevated plus maze) are easily integrated into the pre-encounter-defensive phase as they all relate to exploration in a potentially dangerous environment. These behaviors help ensure that danger is not encountered. Dark or open areas are not dangerous themselves; they do not directly harm an animal. Rather, they are places of increased vulnerability to harm such as an attack by predators.

Behavior will change dramatically when an actual threat is encountered. "Post-encounter defense" is driven by sensory events that activate the amygdala-PAG network (Fanselow 1994; Price 2005) outlined in Figure 1. In essence, when an actual threat is detected or perceived to be highly imminent, the amygdala promotes behaviors that reduce the likelihood of contact with the threat. These survival actions are initiated by controlling midbrain systems, such as the ventrolateral PAG (vPAG), to evoke freezing and analgesia (Fanselow 1991, 1994; LeDoux 1996). For the small, relatively slow and weak rodent, freezing is a particularly effective strategy and dominates this stage of defense. Nonmoving prey are less likely to be detected and less likely to be attacked when detected than moving prey.
If a species' post-encounter defense was always effective, its predators would eventually starve. So the presence of predators in and of itself suggests that the rat may have evolved unique behaviors designed to protect after contact with a predator has happened. Blanchard et al. (1980) found that rats have specific biting patterns directed at cats, which in male rats require that contact be accompanied by pain. This constellation of behaviors that occur at the time of contact we call "circa-strike behaviors." They include protean escape behavior, jumping, and audible vocalization (Fanselow and Lester 1988; Blanchard and Blanchard 1990). Anatomically, circa-strike behavior corresponds to the inhibition of forebrain circuits, with midbrain regions such as the dorsolateral PAG becoming dominant (Fanselow 1991; Depaulis et al. 1992). A key source of sensory information guiding circa-strike defense is the superior colliculus (Dean et al. 1989).

Predatory imminence effects have also been demonstrated in humans. One study showed that viewing unpleasant stimuli generates defensive reactions, and these responses may be at least partially responsible for the effect of the emotional modulation observed in a computerized reaction time (RT) paradigm. Fernandes et al. (2013) investigated these modulatory effects on RT by presenting threatening stimuli (i.e., firearms) and manipulated perceived threat direction (either toward or away from the participant) to prompt different defensive responses. The results demonstrated that threatening stimuli directed toward the observer produced a decrease in RT; in contrast, threat stimuli directed away from the observer produced an increase in RT when compared with neutral stimuli.

Moreover, another study showed proximity effects during evasion of a predator, in which brain activity switches from prefrontal cortical areas to midbrain areas as a predator comes closer (Mobbs et al. 2009). The group used functional magnetic resonance imaging (fMRI) to investigate the neural organization of anticipation and avoidance of artificially intelligent predators with high or low probability of capturing the subject across the spectrum of threat proximity in a video game setting. Post-encounter threat, which was simulated by using different color contexts that indicated increasing probability of encountering the predator, elicited activity in forebrain areas, including subgenual anterior cingulate cortex (sgACC), hippocampus, and amygdala. Conversely, circa-strike threat, which was simulated by meeting and being chased by the predator, increased activity in mid-dorsal ACC and midbrain areas. They also used an indirect measure of panic, locomotor errors, which increased during circa-strike threat and a high probability of being captured. These panic-related locomotor errors were correlated with midbrain activity. These findings support models suggesting that higher forebrain areas are involved in early-threat responses, including the assessment and control of fear, whereas highly imminent danger results in fast, nonassociative defensive reactions mediated by the midbrain (Humphries and Driver 1970; Fanselow and Lester 1988; Mobbs et al. 2009).

The predatory imminence continuum describes the precipitating events of this condition in terms of both threat 
characterization and corresponding circuitry. Each of the three modes of defense has unique antecedent conditions and they engage distinct sets of behaviors. The three modes-pre-encounter, post-encounter, and circa-strike-map well onto disorders of anxiety, fear, and panic, respectively, with respect to both neural circuitry and behavioral responses in both humans and animals. Importantly, these modes may interact in order to modulate one another. For example, if the animal survives after a circa-strike encounter, this may enhance pre-encounter situations where the animal may have an inappropriate perception of threat proximity, and may therefore use the wrong responses for this situation (either post-encounter or circa-strike encounter responses); we argue that these instances may lead to the development of an anxiety or panic disorder. From this perspective, anxiety disorders are a distortion of predatory imminence, such that defensive behaviors intrude into the normal daily range of activities. That is, a greater perception of imminent threat is the central problem of anxiety disorders, not necessarily the capacity to inhibit fear (see the "Inhibiting Fear" section).

The Predatory Imminence Theory best captures the distinction of fear and anxiety, as well as panic, in terms of both cause and effect. In terms of the NIMH RDoc the idea that anxiety relates to potential threat is a specific reference to pre-encounter defense. The RDoc's characterization of fear being a response to acute threat is a reference to post-encounter defense.

\section{Inhibiting fear: extinction and exposure therapy}

Treatment of fear and anxiety disorders, namely exposure therapy, is based on principles of extinction in the laboratory. With this procedure, a CS previously linked to an aversive US is presented alone for a number of trials until the subject learns that the CS no longer predicts the US (Bouton 2002; Myers and Davis 2002). Exposure therapy alone has had moderate success in treating these disorders. It should be noted that because Predatory Imminence Theory suggests that fear and anxiety disorders fall along the predatory imminence spectrum (see the "Predatory Imminence Theory" section), these therapies should be viewed not necessarily as limiting fear, but as shifting along the spectrum. That is, if anxiety disorders are caused by a greater perception of threat, exposure and extinction therapies should aim to create a more accurate representation of the proximity of the threat.

Exposure therapy can be facilitated using other behavioral and pharmacological methods. For example, extinction may be improved by destabilizing a fear memory and reinterpreting it as safe by presenting an isolated retrieval trial prior to extinction (Monfils et al. 2009). Damage to mPFC, especially the ventralmost portion of this region (vmPFC), significantly alters the ability of rats to undergo extinction learning (Morgan et al. 1993; Morgan and LeDoux 1995). Neural activity increases in the mPFC (specifically IL) as extinction is learned (Milad and Quirk 2002); reciprocal connections from IL to BLA are thought to mediate extinction learning. Furthermore, it has been demonstrated that NMDA receptor antagonists in the amygdala disrupt extinction and that facilitation of NMDA receptor function with d-cycloserine enhances context-specific extinction (Walker and Davis 2002; Walker et al. 2002). This work has implications for the treatment of fear disorders; administration of d-cycloserine to humans prior to exposure therapy for the treatment of phobia enhances the treatment response (Ressler et al. 2004).

Other targets have shown to be promising in reducing the likelihood of recovery of fear after extinction. CRH system and the BNST are also critical for extinction of fear, and both lesions of the BNST and CRH antagonist infusions into this area attenuate reinstatement of extinguished fear, or the return of an extinguished CR after reexposure to the US. Therefore, it is suggested that $\mathrm{CRH}$ acting on this site is involved in this form of relapse (Waddell et al. 2006). Renewal of extinguished fear, or the return of the CR after a change of context after extinction, is mediated by hippocampal projections to the BLA, either directly or through PL, which may provide targets to block this fear recovery after extinction (Orsini et al. 2011; see Neural Circuitry section). Moreover, disrupting contextual processing during extinction with a cholinergic antagonist blocked subsequent fear renewal (Zelikowsky et al. 2013). This may be a clinically promising adjunct to exposure therapy by making extinction more relapseresistant.

\section{Conclusions}

Our premise was that if fear and anxiety are truly useful distinct concepts, they should differ in terms of both their causes and their effects on behavior. We reviewed several neurobiological models that have been applied to the distinction between fear and anxiety. These approaches pointed to several changes in defensive behaviors and their underlying circuitry that may have important relevance to anxiety disorders. However, the majority of these models failed in the same way-to identify behaviors that adequately distinguished the two states. Indeed, these models all tended to use the same behavioral index for both fear and anxiety. In each case, the endpoint from these models is the presence or absence of defensive behavior (i.e., freezing), violating the definitional requirement that, if truly distinct, the read-out of fear and anxiety should look different. One approach, innate measures of anxiety, described a rich set of behaviors that are unique to anxiety, such as the elevated plus and light-dark box. However, this approach was weak on specifying the precise conditions that provoke fear versus anxiety.

The one model that met the requirements of an adequate differential definition was predatory imminence. This model viewed anxiety, fear and panic as related to the behavioral modes of pre-encounter, post-encounter, and circa-strike defense. Pre-encounter is characterized by changes in exploration that capture what is observed with the innate anxiety measures as well as changes in normal activity patterns such as meal taking. Postencounter, which is the mode of defense tapped into by most Pavlovian fear-conditioning procedures, is dominated by freezing behavior in rodents. Circa-strike behavior corresponds to the more frantic protean behavior that is seen as an unconditional reaction to shock. Importantly, this model not only differentiates behavior but also specifies when these modes will be activated or suppressed. Changes in the psychological distance from contact with the predator controls response mode selection. While an obviously important determinant of psychological distance is actual spatial distance, other factors influence psychological distance. So as shown in Figure 3, movement down the predatory imminence continuum can be caused by changing the density of the shock schedule. Even with spatial distance, behavior is not only influenced by how far the threat is but what the specific threat is, with greater threats being treated as closer than more minor threats. It should be noted, however, that the other specific laboratory models described do not stand in contrast to Predatory Imminence Theory, but rather provide a means of studying defensive behaviors that characterize specific points along the predatory imminence continuum.

This conceptualization points out that our understanding of fear and anxiety related behavior is rather unbalanced. For postencounter defense (fear), we know a tremendous amount about the anatomical circuits and molecular mechanisms. Our knowledge about pre-encounter defense (anxiety) and circa-strike behavior (panic) is still in its infancy. 


\section{Acknowledgments}

M.S.F. was supported by RO1 MH62122.

\section{References}

Amat J, Matus-Amat P, Watkins LR, Maier SF. 1998. Escapable and inescapable stress differentially alter extracellular levels of 5-HT in the basolateral amygdala of the rat. Brain Res 812: 113-120.

American Psychiatric Association. 2013. Diagnostic and statistical manual V. American Psychiatric Press, Washington, DC.

Annau Z, Kamin LJ. 1961. The conditioned emotional response as a function of intensity of the US. J Comp Physiol Psychol 54: 428-432.

Asede D, Bosch D, Lüthi A, Ferraguti F, Ehrlich I. 2015. Sensory inputs to intercalated cells provide fear-learning modulated inhibition to the basolateral amygdala. Neuron 86: 541-554.

Bailey KR, Crawley JN. 2009. Anxiety-related behaviors in mice. In Methods of behavior analysis in neuroscience, 2nd ed. (ed. Buccafusco JJ), CRC Press, Boca Raton, FL, USA.

Barot SK, Chung A, Kim JJ, Bernstein IL. 2009. Functional imaging of stimulus convergence in amygdalar neurons during Pavlovian fear conditioning. PLoS One 4: e6156.

Blanchard DC, Blanchard RJ. 1990. Behavioral correlates of chronic dominance-subordination relationships of male rats in a seminatural situation. Neurosci Biobehav Rev 14: 455-462.

Blanchard RJ, Kleinschmidt CF, Fukunaga-Stinson C, Blanchard DC. 1980. Defensive attack behavior in male and female rats. Anim Learn Behav 8: $177-183$.

Blanchard RJ, Blanchard DC, Hori K. 1989. Ethoexperimental approaches to the study of defensive behavior. In Ethoexperimental approaches to the study of behavior (ed. Blanchard RJ, Brain PF, Blanchard DC, Parmigani S), pp. 114-136. Kluwer Academic, Dordrecht, The, Netherlands.

Bolles RC. 1970. Species-specific defense reactions and avoidance learning. Psychol Rev 77: 32-48.

Bolles RC. 1975. Theory of motivation, 2nd ed. Harper and Row, New York.

Bolles RC, Fanselow MS. 1980. A perceptual-defensive-recuperative model of fear and pain. Behav Brain Sci 3: 291-301.

Bouton ME. 2002. Context, ambiguity, and unlearning: sources of relapse after behavioral extinction. Biol Psychiatry 10: 976-986.

Chung A, Barot SK, Kim JJ, Bernstein IL. 2011. Biologically predisposed learning and selective associations in amygdalar neurons. Learn Mem 18: $371-374$.

Davis M, Walker DL, Lee Y. 1997. Roles of the amygdala and bed nucleus of the stria terminalis in fear and anxiety measured with the acoustic startle reflex. Possible relevance to PTSD. Ann N Y Acad Sci 821: $305-331$.

Dean P, Redgrave P, Westby GW. 1989. Event or emergency? Two response systems in the mammalian superior colliculus. Trends Neurosci 12: 137-147.

Depaulis A, Keay KA, Bandler R. 1992. Longitudinal neuronal organization of defensive reactions in the midbrain periaqueductal gray region of the rat. Exp Brain Res 90: 307-318.

Domjan M. 1994. Formation of a behavior system for sexual conditioning. Psychol Bull Rev 1: 421-428.

Estes WK, Skinner BF. 1941. Some quantitative properties of anxiety. J Exp Psychol 29: 390.

Fanselow MS. 1981. Naloxone and Pavlovian fear conditioning. Learn Motiv 12: $398-419$.

Fanselow MS. 1984. What is conditioned Fear? Trends Neurosci 7: 460-462.

Fanselow MS. 1989. The adaptive function of conditioned defensive behavior: an ecological approach to Pavlovian stimulus substitution theory. In Ethoexperimental approaches to the study of behavior (ed. Blanchard RJ, Brain PF, Blanchard DC, Parmigiani S), pp. 151-166. Kluwer Academic Publishers, Boston, MA.

Fanselow MS. 1991. The midbrain periaqueductal gray as a coordinator of action in response to fear and anxiety. In The Midbrain periaqueductal grey matter: functional, anatomical and immuno-histohistochemical organization (NATO ASI Series) (ed. Depaulis A, Bandler R), pp. 151-173. Plenum Publishing Corp, New York.

Fanselow MS. 1994. Neural organization of the defensive behavior system responsible for fear. Psychon Bull Rev 1: 429-438.

Fanselow MS, Bolles RC. 1979a. Triggering of the endorphin analgesic reaction by a cue previously associated with shock: reversal by naloxone. Bull Psychol Soc 14: 88-90.

Fanselow MS, Bolles RC. 1979b. Naloxone and shock elicited freezing in the rat. J Comp Physiol Psychol 93: 736-744.

Fanselow MS, Kim JJ. 1994. Acquisition of contextual Pavlovian fear conditioning is blocked by application of an NMDA receptor antagonist D,L-2-amino-5-phosphonovaleric acid to the basolateral amygdala. Behav Neurosci 108: 210-212.
Fanselow MS, Lester LS. 1988. A functional behavioristic approach to aversively motivated behavior: predatory imminence as a determinant of the topography of defensive behavior. In Evolution and learning (ed. Bolles RC, Beecher MD), pp. 185-211. Erlbaum, Hillsdale, NJ.

Fanselow MS, Sigmundi RA. 1986. Species specific danger signals, endogenous opioid analgesia, and defensive behavior. J Exp Psychol Anim Behav Process 12: 301-309.

Fanselow MS, Lester LS, Helmstetter FJ. 1988. Changes in feeding and foraging patterns as an antipredator defensive strategy: a laboratory simulation using aversive stimulation in a closed economy. J Exp Anal Behav 50: $361-374$.

Fernandes O Jr, Portugal LCL, Alves RCS, Campagnoli RR, Mocaiber I, David IPA, Erthal FCS, Volchan E, de Oliveira L, Pereira MG. 2013. How you perceive threat determines your behavior. Front Hum Neurosci 7: 632.

Grahn RE, Will MJ, Hammack SE, Maswood S, McQueen MB, Watkins LR, Maier SF. 1999. Activation of serotonin-immunoreactive cells in the dorsal raphe nucleus in rats exposed to an uncontrollable stressor. Brain Res 826: $35-43$.

Hammack SE, Schmid MJ, LoPresti ML, Der-Avakian A, Pellymounter MA, Foster AC, Watkins LR, Maier SF. 2002. Corticotropin releasing hormone type 2 receptors in the dorsal raphe nucleus mediate the behavioral consequences of uncontrollable stress. J Neurosci 23: 1019-1025.

Haubensak W, Kunwar PS, Cai H, Ciocchi S, Wall NR, Ponnusamy R, Biag J, Dong HW, Deisseroth K, Callaway EM, et al. 2010. Genetic dissection of an amygdala microcircuit that gates conditioned fear. Nature 468: $270-276$.

Helmstetter FJ, Fanselow MS. 1993. Aversively motivated changes in meal patterns of rats in a closed economy: the effects of shock density. Anim Learn Behav 21: 168-175.

Hoffman AN, Lorson NG, Sanabria F, Foster Olive M, Conrad CD. 2014 Chronic stress disrupts fear extinction and enhances amygdala and hippocampal Fos expression in an animal model of post-traumatic stress disorder. Neurobiol Learn Mem 112: 139-147.

Hübner C, Bosch D, Gall A, Lüthi A, Ehrlich I. 2014. Ex vivo dissection of optogenetically activated $\mathrm{mPFC}$ and hippocampal inputs to neurons in the basolateral amygdala: implications for fear and emotional memory. Front Behav Neurosci 8: 64

Humphries DA, Driver PM. 1970. Protean defence by prey animals. Oecologia (Berl) 5: 285-302.

Johansen JP, Tarpley JW, LeDoux JE, Blair HT. 2010. Neural substrates for expectation-modulated fear learning in the amygdala and periaqueductal gray. Nat Neurosci 13: 979-986.

Kamin LJ. 1969. Predictability, surprise, attention, and conditioning. In Punishment and aversive behavior (ed. Campbell BA, Church RM). Appleton-Century-Crofts, New York.

Kim JJ, Fanselow MS. 1992. Modality-specific retrograde amnesia of fear. Science. 256: 675-677.

Kunwar PS, Zelikowsky M, Remedios R, Cai H, Yilmaz M, Meister M, Anderson DJ. 2015. Ventromedial hypothalamic neurons control a defensive emotion state. Elife 4

Landeira-Fernandez J, Decola JP, Kim JJ, Fanselow MS. 2006. Immediate shock deficit in fear conditioning: effects of shock manipulations. BehavNeurosci 120: $873-879$

LeDoux JE. 1996. The emotional brain. Simon and Schuster, New York.

LeDoux JE. 2014. Coming to terms with fear. Proc Natl Acad Sci 111: 2871-2878

Lee Y, Davis M. 1997. Role of the hippocampus, the bed nucleus of the stria terminalis and the amygdala in the excitatory effect of corticotropin releasing hormone (CRH) on the acoustic startle reflex. J Neurosci 17: 6434-6446.

Li YQ, Jia HG, Rao ZR, Shi JW. 1990. Serotonin-, substance P- or leucine-enkephalin-containing neurons in the midbrain periaqueductal gray and nucleus raphe dorsalis send projection fibers to the central amygdaloid nucleus in the rat. Neurosci Lett 120: 124-127.

Likhtik E, Popa D, Apergis-Schoute J, Fidacaro GA, Paré D. 2008. Amygdala intercalated neurons are required for expression of fear extinction. Nature 454: 642-645.

Long VA, Fanselow MS. 2012. Stress enhanced fear learning in rats is resistant to the effects of immediate massed extinction. Stress 15: $627-636$.

Maier SF. 1984. Learned helplessness and animal models of depression. Prog Neuropsychopharmacol Biol Psychiatry 8: 435-446.

Maier SF. 1990. Role of fear in mediating shuttle escape learning deficit produced by inescapable shock. J Exp Psychol Anim Behav Process 16: $137-149$.

Maier SF, Watkins LR. 1998. Cytokines for psychologists: implications of bidirectional immune-to-brain communication for understanding behavior, mood, and cognition. Psychol Rev 105: 83-107.

Maier SF, Grahn RE, Kalman BA, Sutton LC, Wiertelak EP, Watkins LR. 1993. The role of the amygdala and dorsal raphe nucleus in mediating the 
behavioral consequences of inescapable shock. Behav Neurosci 107: 377-388.

Maren S, Fanselow MS. 1995. Synaptic plasticity in the basolateral amygdala induced by hippocampal formation stimulation in vivo. J Neurosci 15: $7548-7564$.

Maswood S, Barter JE, Watkins LR, Maier SF. 1998. Exposure to inescapable but not escapable shock increases extracellular levels of 5-HT in the dorsal raphe nucleus of the rat. Brain Res 783: 115-120.

Meyer EM, Long VA, Fanselow MS, Spigelman I. 2013. Stress increases voluntary alcohol intake, but does not alter established drinking habits in a rat model of posttraumatic stress disorder. Alcohol Clin Exp Res 37: $566-574$.

Milad MR, Quirk GJ. 2002. Neurons in medial prefrontal cortex signal memory for fear extinction. Nature 420: 70-74.

Miserendino MJ, Sananes CB, Melia KR, Davis M. 1990. Blocking of acquisition but not expression of conditioned fear-potentiated startle by NMDA antagonists in the amygdala. Nature 345: 716-718.

Mobbs D, Marchant JL, Hassabis D, Seymour B, Tan G, Gray M, Petrovic P, Dolan RJ, Frith CD. 2009. From threat to fear: the neural organization of defensive fear systems in humans. J Neurosci 9: 12236-12243.

Monfils MH, Cowansage KK, Klann E, LeDoux JE. 2009.

Extinction-reconsolidation boundaries: key to persistent attenuation of fear memories. Science 324: 951-955.

Morgan MA, LeDoux JE. 1995. Differential contribution of dorsal and ventral medial prefrontal cortex to the acquisition and extinction of conditioned fear in rats. Behav Neurosci 109: 681-688.

Morgan MA, Romanski LM, LeDoux JE. 1993. Extinction of emotional learning: contribution of medial prefrontal cortex. Neurosci Lett 163: 109-113.

Myers KM, Davis M. 2002. Behavioral and neural analysis of extinction. Neuron 36: $567-584$.

National Institute of Mental Health. 2013. Research Domain Criteria [RDoc] http://www.nimh.nih.gov/research-priorities/rdoc/index shtmfl.

Orsini CA, Kim JJ, Knapska E, Maren S. 2011. Hippocampal and prefrontal projections to the basal amygdala mediate contextual regulation of fear after extinction. J Neurosci 31: 17269-17277.

Paré D, Quirk GJ, LeDoux JE. 2004. New vistas on amygdala networks in conditioned fear. I Neurophysiol 92: 1-9.

Pinel JP, Mumby DG, Dastur FN, Pinel JG. 1994. Rat (Rattus norvegicus) defensive behavior in total darkness: risk-assessment function of defensive burying. J Comp Psychol 108: 140-147.

Pinto A, Sesack SR. 2000. Limited collateralization of neurons in the rat prefrontal cortex that project to the nucleus accumbens. Neuroscience 97: 635-642.

Pinto A, Sesack SR. 2008. Ultrastructural analysis of prefrontal cortical inputs to the rat amygdala: spatial relationships to presumed dopamine axons and D1 and D2 receptors. Brain Struct Funct 213: 159-175.

Pitkanen A, Savander V, LeDoux JE. 1997. Organization of intra-amygdaloid circuitries in the rat: an emerging framework for understanding functions of the amygdala. Trends Neurosci 20: $517-523$.

Poulos AM, Ponusamy R, Dong HW, Fanselow MS. 2010. Compensation in the neural circuitry of fear conditioning awakens learning circuits in the bed nuclei of the stria terminalis. Proc Natl Acad Sci 107: 14881-14886.

Poulos AM, Reger M, Mehta N, Zhuravka I, Sterlace SS, Gannam C, Hovda DA, Giza CC, Fanselow MS. 2014. Amnesia for early life stress does not preclude the adult development of posttraumatic stress disorder symptoms in rats. Biol Psychiatry 76: 306-314.

Price JL. 2005. Free will versus survival: brain systems that underlie intrinsic constraints on behavior. J Comp Neurol 493: 132-139.

Quinn JJ, Skipper RA, Claflin DI. 2014. Infant stress exposure produces persistent enhancement of fear learning across development. Dev Psychobiol 56: 1008-1016.

Quirk GJ, Likhtik E, Pelletier JG, Paré D. 2003. Stimulation of medial prefrontal cortex decreases the responsiveness of central amygdala output neurons. J Neurosci 23: 8800-8807.

Rau V, Fanselow MS. 2009. Exposure to a stressor produces a long lasting enhancement of fear learning in rats. Stress 12: 125-133.

Rau V, De Cola JP, Fanselow MS. 2005. Stress-induced enhancement of fear learning: an animal model of posttraumatic stress disorder. Neurosci Biobehav Rev 29: 1207-1223.
Ressler KJ, Rothbaum BO, Tannenbaum L, Anderson P, Graap K, Zimand E, Hodges L, Davis M. 2004. Cognitive enhancers as adjuncts to psychotherapy: use of D-cycloserine in phobic individuals to facilitate extinction of fear. Arch Gen Psychiatry 61: 1136-1144.

Rizvi TA, Ennis M, Behbehani MM, Shipley MT. 1991. Connections between the central nucleus of the amygdala and the midbrain periaqueductal gray: topography and reciprocity. J Comp Neurol 303: $121-131$

Rodgers RJ, Shepherd JK. 1993. Influence of prior maze experience on behaviour and response to diazepam in the elevated plus-maze and light/dark tests of anxiety in mice. Psychopharmacology (Berl) 113: 237-242.

Romanski LM, Clugnet MC, Bordi F, LeDoux JE. 1993. Somatosensory and auditory convergence in the lateral nucleus of the amygdala. Behav Neurosci 107: 444-450.

Rudy JW, O'Reilly RC. 1999. Contextual fear conditioning, conjunctive representations, pattern completion, and the hippocampus. Behav Neurosci 113: 867-880.

Senn V, Wolff SB, Herry C, Grenier F, Ehrlich I, Gründemann J, Fadok JP, Müller C, Letzkus JJ, Lüthi A. 2014. Long-range connectivity defines behavioral specificity of amygdala neurons. Neuron 81: 428-437.

Strobel C, Marek R, Gooch HM, Sullivan RK, Sah P. 2015. Prefrontal and auditory input to intercalated neurons of the amygdala. Cell Rep in press.

Timberlake W. 1994. Behavior systems, associationism, and Pavlovian conditioning. Psychon Bull Rev 1: 405-420.

Timberlake W, Fanselow MS. 1994. Symposium on behavior systems: learning, neurophysiology, and development. Psychon Bull Rev 1: 403-404.

Timberlake W, Lucas G. 1989. Behavior systems and learning: from misbehavior to general principles. In Contemporary learning theories: instrumental conditioning theory and the impact on biological constraints on learning (ed. Klein SB, Mower RR), pp. 237-275. Erlbaum, Hillsdale, NJ.

Ventura-Silva AP, Melo A, Ferreira AC, Carvalho MM, Campos FL, Sousa N, Pêgo JM. 2013. Excitotoxic lesions in the central nucleus of the amygdala attenuate stress-induced anxiety behavior. Front Behav Neurosci 7: 32.

Waddell J, Morris RW, Bouton ME. 2006. Effects of bed nucleus of the stria terminalis lesions on conditioned anxiety: aversive conditioning with long-duration conditional stimuli and reinstatement of extinguished fear. Behav Neurosci 120: 324-336.

Walker DL, Davis M. 1997. Double dissociation between the involvement of the bed nucleus of the stria terminalis and the central nucleus of the amygdala in startle increases produced by conditioned versus unconditioned fear. J Neurosci 17: 9375-9383.

Walker DL, Davis M. 2002. The role of amygdala glutamate receptors in fear learning, fear-potentiated startle, and extinction. Pharmocol Biochem Behav 71: 379-392.

Walker DL, Ressler KJ, Lu KT, Davis M. 2002. Facilitation of conditioned fear extinction by systemic administration or intra-amygdala infusions of D-cycloserine as assessed with fear-potentiated startle in rats. J Neurosci 22: 2343-2351.

Walker DL, Toufexis DJ, Davis M. 2003. Role of the bed nucleus of the stria terminalis versus the amygdala in fear, stress, and anxiety. Eur J Pharmacol 463: 199-216.

Walther FR. 1969. Flight behavior and avoidance of predators in Thomson's gazelle (Gazellathomsoni Guenther 1884). Behaviour 34: $184-221$.

Watson JB, Rayner R. 1920. Conditioned emotional reactions. Am Psychol 55: $313-317$

Young SL, Fanselow MS. 1992. Associative regulation of Pavlovian fear conditioning: unconditional stimulus intensity, incentive shifts, and latent inhibition. J Exp Psychol Anim Behav Process 18: 400-413.

Zelikowsky M, Hast TA, Bennett RZ, Merjanian M, Nocera NA, Ponnusamy R, Fanselow MS. 2013. Cholinergic blockade frees fear extinction from its contextual dependency. Biol Psychiatry 73: $345-352$.

Received May 18, 2015; accepted in revised form July 9, 2015. 


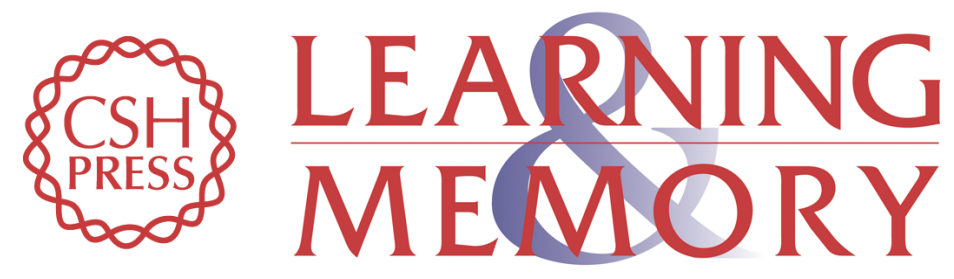

\section{Neurobehavioral perspectives on the distinction between fear and anxiety}

Jennifer N. Perusini and Michael S. Fanselow

Learn. Mem. 2015, 22:

Access the most recent version at doi:10.1101/Im.039180.115

References This article cites 84 articles, 11 of which can be accessed free at: http://learnmem.cshlp.org/content/22/9/417.full.html\#ref-list-1

Creative This article is distributed exclusively by Cold Spring Harbor Laboratory Press for the Commons License first 12 months after the full-issue publication date (see

http://learnmem.cshlp.org/site/misc/terms.xhtml). After 12 months, it is available under a Creative Commons License (Attribution-NonCommercial 4.0 International), as described at http://creativecommons.org/licenses/by-nc/4.0/.

Email Alerting Receive free email alerts when new articles cite this article - sign up in the box at the Service top right corner of the article or click here. 